Virginia Commonwealth University VCU Scholars Compass

2010

\title{
Magnetic moment and local moment alignment in anionic and/or oxidized Fen clusters
}

D. R. Roy

Virginia Commonwealth University

R. Robles

Virginia Commonwealth University

S. N. Khanna

Virginia Commonwealth University, snkhanna@vcu.edu

Follow this and additional works at: http://scholarscompass.vcu.edu/phys_pubs

Part of the Physics Commons

Roy, D. R., Robles, R., Khanna, S. N. Magnetic moment and local moment alignment in anionic and/or oxidized Fen clusters. The Journal of Chemical Physics 132, 194305 (2010). Copyright @ 2010 AIP Publishing LLC.

\section{Downloaded from}

http://scholarscompass.vcu.edu/phys_pubs/201

This Article is brought to you for free and open access by the Dept. of Physics at VCU Scholars Compass. It has been accepted for inclusion in Physics Publications by an authorized administrator of VCU Scholars Compass. For more information, please contact libcompass@vcu.edu. 


\title{
Magnetic moment and local moment alignment in anionic and/or oxidized $\mathrm{Fe}_{\mathrm{n}}$ clusters
}

\author{
D. R. Roy, R. Robles, and S. N. Khanna ${ }^{a}$ \\ Department of Physics, Virginia Commonwealth University, Richmond, Virginia 23284-2000, USA
}

(Received 12 February 2010; accepted 14 April 2010; published online 18 May 2010)

\begin{abstract}
First principles studies on the ground state structure, binding energy, spin multiplicity, and the noncollinearity of local spin moments in $\mathrm{Fe}_{\mathrm{n}}$ and $\mathrm{Fe}_{\mathrm{n}}{ }^{-}$clusters and their oxides, viz., $\mathrm{Fe}_{\mathrm{n}} \mathrm{O}_{2}$ and $\mathrm{Fe}_{\mathrm{n}} \mathrm{O}_{2}{ }^{-}$have been carried out within a density functional formalism. The ground states of $\mathrm{Fe}_{\mathrm{n}}$ and $\mathrm{Fe}_{\mathrm{n}}{ }^{-}$clusters have collinear spins with a magnetic moment of around $3.0 \mu_{\mathrm{B}}$ per atom. The $\mathrm{O}_{2}$ molecule is found to be dissociatively absorbed and its most significant effect on spin occurs in $\mathrm{Fe}_{2}$, where $\mathrm{Fe}_{2} \mathrm{O}_{2}$ and $\mathrm{Fe}_{2} \mathrm{O}_{2}{ }^{-}$show antiferromagnetic and noncollinear spin arrangements, respectively. The calculated adiabatic electron affinity and the vertical transitions from the anion to the neutral species are found to be in good agreement with the available negative ion photodetachment spectra, providing support to the calculated ground states including the noncollinear ones. (0) 2010 American Institute of Physics. [doi:10.1063/1.3425879]
\end{abstract}

\section{INTRODUCTION}

The magnetic properties of small clusters of itinerant ferromagnetic elements (iron, cobalt, and nickel) have been the subject of numerous experimental and theoretical investigations. ${ }^{1-28}$ In particular, the iron based clusters have attracted considerable attention. ${ }^{1-22}$ On the experimental side, Stern-Gerlach deflection experiments have provided information on the anisotropy and magnetic moment while the first principles electronic structure calculations have been used to determine the geometry, electronic structure, and magnetic moments of small clusters. The main findings from these efforts can be summarized as follows. (1) Starting from the bulk, the initial reduction in size leads to enhancement of magnetic moment per atom until cluster sizes approach a few dozen atoms. (2) At small sizes, the quantum effects become significant and the magnetic moment exhibits nonmonotonic variations with size with some clusters exhibiting much larger moment per atom than in the bulk. (3) The reduction in size results in reduction in magnetic anisotropy and small clusters are superparamagnetic with blocking temperatures much less than room temperature. While these findings are significant, there has been limited focus on another important feature at small sizes, namely, imperfect alignment of the local atomic moments. ${ }^{29-36}$ This is particularly relevant for iron as the studies ${ }^{33}$ indicate that bulk fcc iron has an antiferromagnetic ground state while the bcc iron is ferromagnetic. Hence, examination of noncollinear configurations is necessary to ascertain the magnetic ordering in the ground states.

It was almost 12 years ago that Oda et al..$^{34}$ investigated noncollinear magnetism in iron clusters using a plane wave pseudopotential scheme within a generalized density functional theory (DFT). Their investigations, based on local density approximation for exchange and correlation, concluded

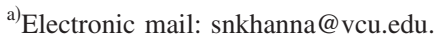

that a linear metastable $\mathrm{Fe}_{3}$ as well as distorted triangular bipyramid $\mathrm{Fe}_{5}$ in ground state both have noncollinear arrangements of local spins. These findings motivated further investigations. In particular, Hobbs et al. ${ }^{35}$ studied the noncollinear magnetism in $\mathrm{Fe}_{\mathrm{n}}$ and $\mathrm{Cr}_{\mathrm{n}}$ clusters for $\mathrm{n} \leq 5$. They also found a noncollinear ground state of $\mathrm{Fe}_{5}$ with a total magnetic moment of $14.5 \mu_{\mathrm{B}}$. These findings are in disagreement with recent work by Rollmann et al. ${ }^{36}$ using generalized gradient approximation (GGA) functional within DFT. Rollmann et al. predicted that the noncollinear $\mathrm{Fe}_{5}$ is a metastable structure with a total magnetic moment of 15.9 $\mu_{\mathrm{B}}$ whereas collinear ferromagnetic $\mathrm{Fe}_{5}$ is the ground state after a relaxation in the geometry. In addition to pure species, Shiroishi et al. ${ }^{15,16}$ studied noncollinear magnetism of $\mathrm{Fe}_{\mathrm{m}} \mathrm{O}_{\mathrm{n}}(\mathrm{m}=1-4 ; \mathrm{n}=1-6)$ and found $\mathrm{Fe}_{3} \mathrm{O}_{5}{ }^{-}$as possessing a noncollinear ground state. A detailed systematic study of noncollinear magnetism in bare and ligated iron clusters is still missing.

The objective of the present work is to present a systematic study of the magnetic properties of neutral, anionic, and oxidized iron clusters $\left(\mathrm{Fe}_{\mathrm{n}}, \mathrm{Fe}_{\mathrm{n}}^{-}, \mathrm{Fe}_{\mathrm{n}} \mathrm{O}_{2}\right.$, and $\left.\mathrm{Fe}_{\mathrm{n}} \mathrm{O}_{2}^{-}\right)$containing up to eight iron atoms. We are particularly interested in ascertaining the magnetic ordering in the ground state of the pure clusters as well as examining how the addition of an electron or the oxygen ligand changes the overall magnetic moment including the possibility of noncollinearity of the spin magnetic moments at various sites. To make comparisons with experiment, we use our results on the negative ions to compute vertical transitions to neutral species formed after the removal of a majority or minority electron and adiabatic electron affinity (AEA). The transition energies can be directly compared to the experimental spectra in negative ion photodetachment spectroscopy. In these experiments, a massselected cluster anion is crossed with a pulsed laser of fixed wavelength (energy), and photodetached electrons are detected according to their kinetic energies. Imagine that an anionic cluster has $\mathrm{N}$ number of unpaired spins and thus a 
magnetic moment of $N \mu_{\mathrm{B}}$ and a spin multiplicity of $\mathrm{M}=\mathrm{N}$ +1 . As an electron is detached, the neutral cluster can have a spin multiplicity of $\mathrm{M}+1$ or $\mathrm{M}-1$ depending on whether the electron was removed from the minority or the majority spin state. Further, the neutral cluster can be in the lowest or excited state of multiplicity $M \pm 1$. Among the products of cluster anion calculations are the vertical transition energies from the anion to each of these neutral states and the AEA. When a predicted photodetachment transition energy for a given cluster anion quantitatively matches features observed in its photoelectron spectrum, it is reasonable to conclude that the calculation has obtained the correct ground state for both the anion and neutral states involved. In the case of having a noncollinear configuration, the concepts of multiplicity, and majority or minority spin states are no longer defined, but it is still possible to predict the photodetachment transition energy by removing the electron with the highest energy in the anion to get the corresponding neutral state. A detailed procedure will be described later. In this work, we have used the experimental spectra of Leopold and Lineberger ${ }^{1}$ and Wang et al. ${ }^{2}$ for $\mathrm{Fe}_{\mathrm{n}}$ clusters and of Wang et $a l .{ }^{10-12}$ for iron oxides clusters, $\mathrm{Fe}_{\mathrm{n}} \mathrm{O}_{\mathrm{m}}(\mathrm{n}=1-4 ; \mathrm{m}=1-6)$, to substantiate our findings.

Section II is devoted to a discussion of the theoretical methods while Sec. III presents results and a discussion of results. Section IV contains a summary of the key findings and conclusions.

\section{THEORETICAL METHODS}

The theoretical studies were carried out by a projected augmented wave (PAW) method within a density functional formalism. ${ }^{37,38}$ A systematic search for the global minima of $\mathrm{Fe}_{\mathrm{n}}$ and $\mathrm{Fe}_{\mathrm{n}}^{-}(\mathrm{n}=2-8)$ and their oxides, $\mathrm{Fe}_{\mathrm{n}} \mathrm{O}_{2}$ and $\mathrm{Fe}_{\mathrm{n}} \mathrm{O}_{2}^{-}$ $(n=2-8)$, was carried out by starting from several initial configurations and investigating different spin magnetic moments. The studies were carried out using a GGA functional developed by Perdew et al. ${ }^{39}$ as implemented in the Vienna ab initio simulation package (VASP). ${ }^{40,41}$ The interaction between the valence and core electrons is described by PAW method and the wave functions were expanded using a plane wave basis set with a cutoff energy of $400 \mathrm{eV}$. The cubic super cell throughout the calculations is chosen as $15 \times 15$ $\times 15 \AA^{3}$ to make sure that the interaction between the clusters with their images is negligible. The integration over the Brillouin zone is done at the $\Gamma$ point only. In the structural optimization process we relaxed the atoms in the direction of the forces until the forces dropped below a threshold value of $0.01 \mathrm{eV} / \AA ̊$. We included dipole and quadruple corrections in our calculations, which can be especially important for the charged species. A fully noncollinear magnetism density ${ }^{35}$ is allowed to account for the possible noncollinear alignment of the spin moments. The total magnetic moment of the system is calculated as the absolute value of the integrated magnetization density. ${ }^{35}$ To calculate the local magnetic moments we have projected the magnetization density onto a sphere around each of the atoms. Spin-orbit coupling has not been included in our calculations and therefore, our results are invariant with respect to a global rotation of the spin moments.

In this work, we have also carried out studies on anionic species to make contact with the experiments on negative ion photodetachment spectra. In these experiments, the incident photon removes an electron from the cluster and the measurement of the energy of the detached electron along with the photon energy can provide information on the electronic structure of the cluster. ${ }^{1,2,10,11}$ Within the density functional approach used here, the incident photon removes an electron either from the majority or the minority subshells. Consequently, the resulting system has a multiplicity increased or decreased by one. Further, the electron could come from the highest molecular orbital or the deeper states of the majority or minority shell and this can lead to multiple peaks in the spectrum. Generally, the first two peaks correspond to the vertical transitions from the anion to the neutral cluster having multiplicity $\mathrm{M} \pm 1$ and at the same geometry as the anion. Consequently, the difference in energy between the anion and the neutral can provide comparison with the peaks in the spectrum. It is important to highlight that this simplistic approach does have limitations particularly for small transition metal clusters where the calculations of the excited states within the density functional framework and the broadening of the states can complicate the spectra.

\section{RESULTS AND DISCUSSION}

\section{A. $\mathrm{Fe}_{\mathrm{n}}$ and $\mathrm{Fe}_{\mathrm{n}}^{-}(\mathrm{n}=2-8)$}

With the goal of obtaining true magnetic ground state structures, we have used several initial noncollinear structures along with their collinear analogs. ${ }^{42}$ Figure 1 presents the ground state geometries of $\mathrm{Fe}_{\mathrm{n}}$ and $\mathrm{Fe}_{\mathrm{n}}^{-}(\mathrm{n}=2-8)$ clusters along with their corresponding total magnetic moments and the energy gap between the highest occupied molecular orbital and lowest unoccupied molecular orbital (HOMOLUMO) (HLG). There is a small increase in bond length for the anionic dimer $(2.05 \AA)$ compared to its neutral structure. For the iron trimer, the addition of an electron on the neutral cluster leads to the changes its isosceles shape to an equilateral triangle with $C_{3 h}$ symmetry. Both the neutral and anionic $\mathrm{Fe}_{4}$ are a distorted tetrahedron consisting of four similar isosceles triangular faces in each case. The pentamer neutral and anionic clusters are distorted trigonal bipyramid possessing $C_{s}$-symmetry with the variation in bond lengths as $2.28-2.67$ and 2.28-2.60 А, respectively. The clusters containing six iron atoms possess an octahedron shape. The neutral and anionic $\mathrm{Fe}_{7}$ clusters are distorted pentagonal bipyramids. The $\mathrm{Fe}_{8}$ clusters are a bidisphenoid in both of their neutral and anionic forms. The HLG is generally found to be higher in the anionic iron cluster compared to their neutral analogs (Fig. 1). All the ground state structures of the pure neutral and anionic iron clusters considered in the present study are found to be ferromagnetic in nature. The number of unpaired electrons found for the neutral $\mathrm{Fe}_{\mathrm{n}}$ clusters are 6, 10, 14, 16, 20,22 , and 24, respectively, when the cluster size increases from two to eight. It may be noted that the addition of an electron enhances the total magnetic moment up to the cluster size five followed by a decrement for the rest. In order to 
n

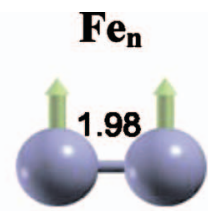

$6 \mu_{\mathrm{B}}$; HLG: $0.25 \mathrm{eV}$

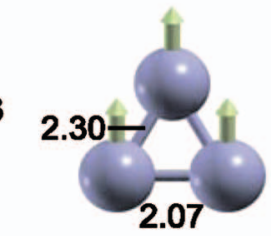

$10 \mu_{B}$; HLG: $0.31 \mathrm{eV}$

4

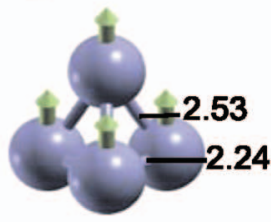

$14 \mu_{\mathrm{B}} ; \mathrm{HLG}: 0.40 \mathrm{eV}$

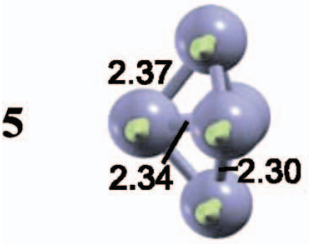

$16 \mu_{\mathrm{B}} ; \mathrm{HLG}: 0.16 \mathrm{eV}$

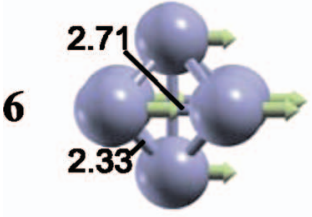

$20 \mu_{\mathrm{B}}$; HLG: $0.42 \mathrm{eV}$

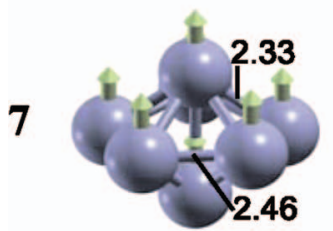

$22 \mu_{\mathrm{B}}$; HLG: $0.37 \mathrm{eV}$

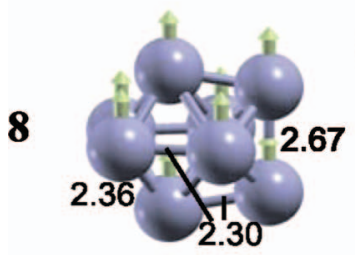

$24 \mu_{\mathrm{B}} ; \mathrm{HLG}: 0.52 \mathrm{eV}$

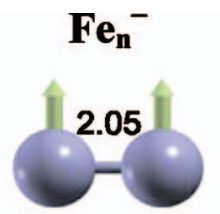

$7 \mu_{\mathrm{B}} ; \mathrm{HLG}: 0.37 \mathrm{eV}$

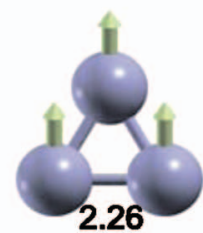

$11 \mu_{\mathrm{B}}$; HLG: $0.56 \mathrm{eV}$

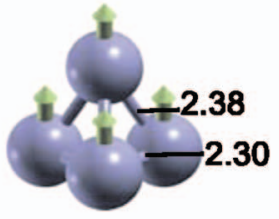

$15 \mu_{\mathrm{B}} ; \mathrm{HLG}: 0.41 \mathrm{eV}$

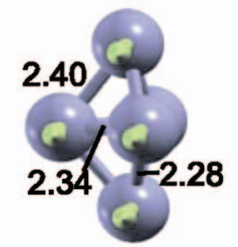

$17 \mu_{\mathrm{B}}$; HLG: $0.55 \mathrm{eV}$

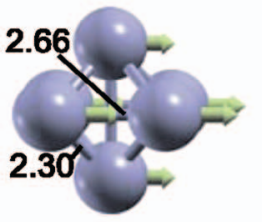

$19 \mu_{\mathrm{B}} ; \mathrm{HLG}: 0.38 \mathrm{eV}$

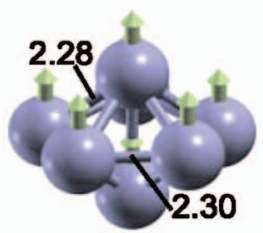

$21 \mu_{\mathrm{B}}$; HLG: $0.71 \mathrm{eV}$

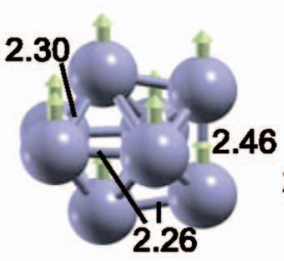

$23 \mu_{\mathrm{B}}$; HLG: $0.68 \mathrm{eV}$

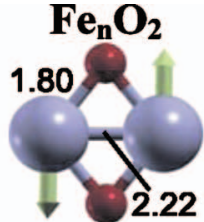

$0 \mu_{\mathrm{B}} ; \mathrm{HLG}: 0.60 \mathrm{eV}$

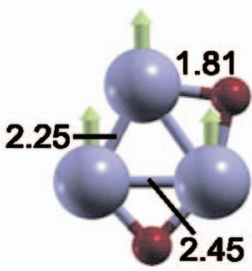

$12 \mu_{\mathrm{B}} ; \mathrm{HLG}: 0.60 \mathrm{eV}$

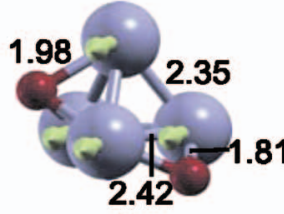

$14 \mu_{B} ; H L G: 0.66 \mathrm{eV}$

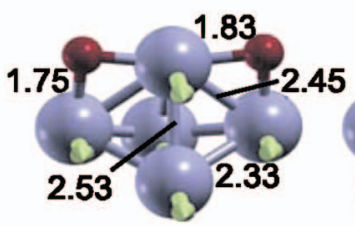

$16 \mu_{\mathrm{B}} ; \mathrm{HLG}: 0.59 \mathrm{eV}$

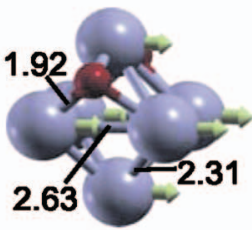

$20 \mu_{\mathrm{B}} ; \mathrm{HLG}: 0.41 \mathrm{eV}$

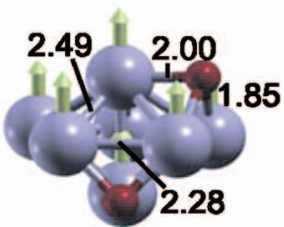

$22 \mu_{\mathrm{B}} ; \mathrm{HLG}: 0.43 \mathrm{eV}$

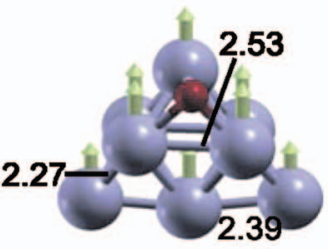

$24 \mu_{\mathrm{B}} ; \mathrm{HLG}: 0.39 \mathrm{eV}$

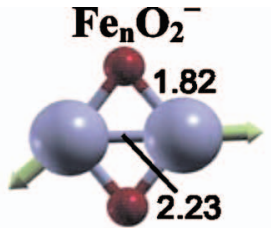

$2.84 \mu_{\mathrm{B}}$; HLG: $0.42 \mathrm{eV}$

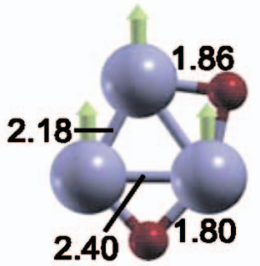

$11 \mu_{\mathrm{B}} ; \mathrm{HLG}: 0.58 \mathrm{eV}$

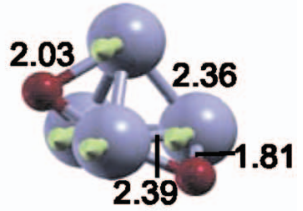

$15 \mu_{\mathrm{B}} ; \mathrm{HLG}: 0.23 \mathrm{eV}$

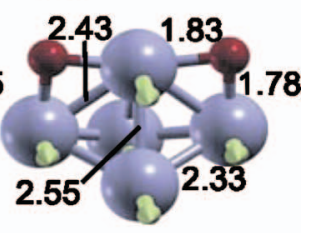

$17 \mu_{\mathrm{B}}$; HLG: $0.27 \mathrm{eV}$

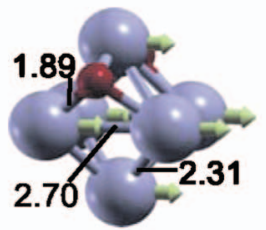

$19 \mu_{\mathrm{B}} ; \mathrm{HLG}: 0.43 \mathrm{eV}$

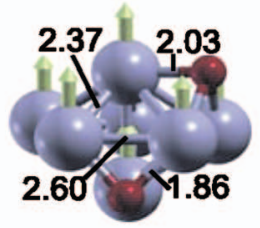

$21 \mu_{\mathrm{B}} ; \mathrm{HLG}: 0.37 \mathrm{eV}$

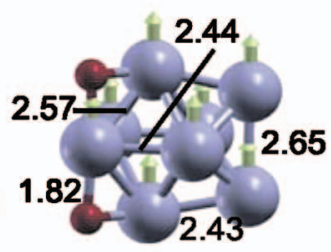

$25 \mu_{\mathrm{B}}$; HLG: $0.34 \mathrm{eV}$

FIG. 1. The total magnetic moment and HLG of the ground state structures of $\mathrm{Fe}_{\mathrm{n}}, \mathrm{Fe}_{\mathrm{n}}{ }^{-}, \mathrm{Fe}_{\mathrm{n}} \mathrm{O}_{2}$, and $\mathrm{Fe}_{\mathrm{n}} \mathrm{O}_{2}{ }^{-}$clusters. The blue (bigger) spheres are the iron atoms while the red (smaller) spheres represent oxygen atoms. The arrows indicate the direction of the local spin moments.

study the relative stability of the iron clusters, we have calculated the binding energy (BE) per atom, as provided in Fig. 2. The $\mathrm{BE}$ per $\mathrm{Fe}$ atom is calculated for $\mathrm{Fe}_{\mathrm{n}}$ and $\mathrm{Fe}_{\mathrm{n}}{ }^{-}$clusters, respectively, as follows:

$$
\mathrm{BE} / \mathrm{atom}=\left[\mathrm{n} E(\mathrm{Fe})-E\left(\mathrm{Fe}_{\mathrm{n}}\right)\right] / \mathrm{n},
$$

$$
\mathrm{BE} / \text { atom }=\left[(\mathrm{n}-1) E(\mathrm{Fe})+E\left(\mathrm{Fe}^{-}\right)-E\left(\mathrm{Fe}_{\mathrm{n}}^{-}\right)\right] / \mathrm{n} .
$$

Although our calculated $\mathrm{BE} /$ atom for $\mathrm{Fe}_{2}(1.35 \mathrm{eV})$ using PAW-GGA method is larger than experimental value $(0.65$ $\mathrm{eV}),{ }^{43}$ it is closer compared to the results by Yu et al. ${ }^{8}(1.55$ 


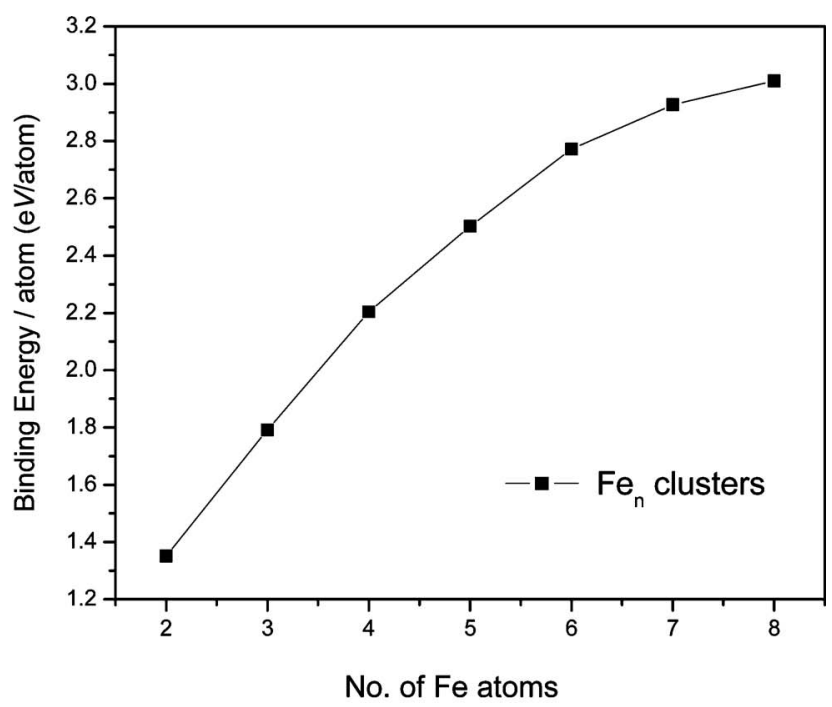

(a)

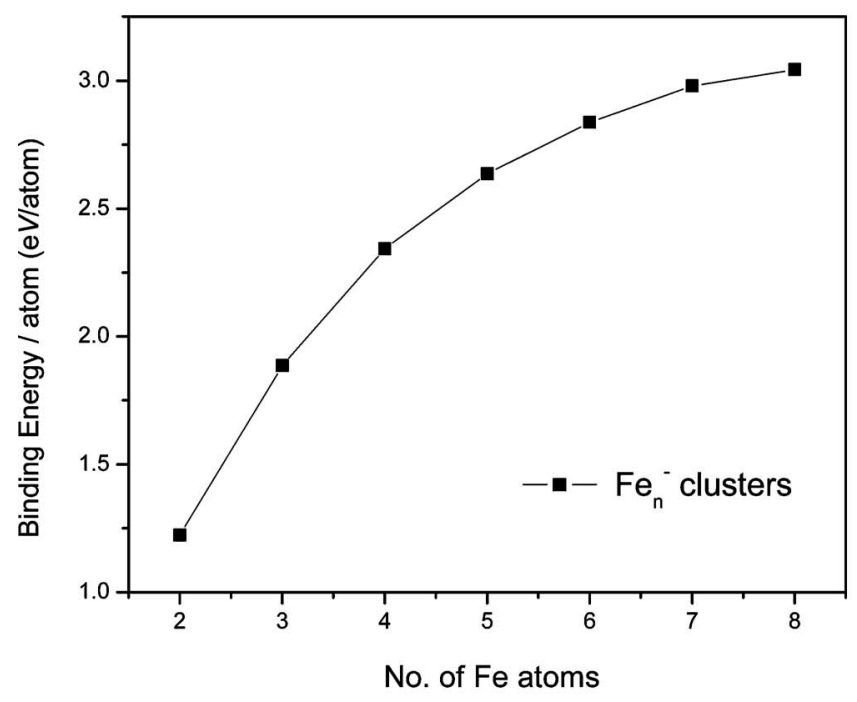

(b)

FIG. 2. The cluster size dependence of $\mathrm{BE}$ of (a) $\mathrm{Fe}_{\mathrm{n}}$ and (b) $\mathrm{Fe}_{\mathrm{n}}^{-}$(n $=2-8)$ clusters.

eV), Diéguez et al..$^{5}(2.25 \mathrm{eV})$, and Köhler et al. ${ }^{7}(2.11 \mathrm{eV})$. The differences in the calculated BEs may be due to the different functionals used under DFT. The BE per bond (BE/ bond) calculation shows that iron binds more tightly in $\mathrm{Fe}_{2}$ and $\mathrm{Fe}_{3}$ (2.70 and $1.79 \mathrm{eV} /$ bond, respectively), whereas for higher sizes BE/bond remains more or less the same (about $1.4 \mathrm{eV} /$ bond). Table I present a comparative study on the total magnetic moment of the present work with some of available literatures. It shows that our prediction exactly matches with some recent DFT-GGA computations, ${ }^{6,36}$ and also agrees with most of the others calculations except a couple of cases for $\mathrm{Fe}_{3},{ }^{3-5,7,34} \mathrm{Fe}_{4},{ }^{3-5,7,8,34}$ and $\mathrm{Fe}_{5} .{ }^{4,34,35}$ The difference is probably due to the use of pseudopotentials, ${ }^{3-5,7,8,34,35}$ whereas our calculations use a more accurate PAW potential. The average magnetic moment shows a small variation around $3.0 \mu_{\mathrm{B}}$, which suggests that the convergence toward the experimental bulk value of $2.15 \mu_{\mathrm{B}}$ requires larger sizes.

In our exploration for the ground state, we have noticed a number of (more than 20) antiferro-/noncollinear magnetic structures. Almost all of them are relatively far in energy, lying within the $0.9-1.6 \mathrm{eV}$ relative energy range with respect to the ground state ferromagnetic structures. ${ }^{42}$ The only exception is the noncollinear $\mathrm{Fe}_{5}$, which is just $0.07 \mathrm{eV}$ higher than the ferromagnetic ground state (Fig. 3). Although $\mathrm{Fe}_{5}$ was found as a noncollinear in ground state, ${ }^{34,35}$ a recent calculation by Rollmann et al. ${ }^{36}$ with the exchange correlation functional as proposed by Perdew and Wang, ${ }^{44}$ showed that when a geometric distortion is allowed, the noncollinear $\mathrm{Fe}_{5}$ with $D_{3 h}$ geometry and a total magnetic moment of $15.9 \mu_{\mathrm{B}}$ reveals as a metastable state, whereas a ferromagnetic counterpart is the ground state, having the geometry of a distorted trigonal bipyramid and a total magnetic moment of $16 \mu_{\mathrm{B}}$. Our present calculations agree with Rollmann's findings.

As mentioned earlier, an indirect approach to determine the magnetic moment of small clusters is to compare the calculated vertical transitions VDE-1 and VDE-2 from the anion ground state to the neutral species. Table II shows the experimental and our calculated AEA and vertical detachment energy (VDE) for the $\mathrm{Fe}_{\mathrm{n}}(\mathrm{n}=2-8)$ clusters. The AEA is calculated as the total energy difference between the ground state anionic and neutral clusters. It may be noted that for $n=2-7$, our calculated AEA shows excellent agreement with the experimental results, and the remaining one $(\mathrm{n}=8)$ is not far $(\sim 0.2 \mathrm{eV})$ from the experimental value. Moreover, for $n=8$, both calculated VDEs show very good match with the corresponding experimental values confirming the prediction of the structure. The VDEs of all the other predicted structures are found to be a good correspondence to their experimental observations using photoelectron spectroscopy ${ }^{1,2}$ except for the VDE-2 of $\mathrm{Fe}_{3}$, which may be understood due to the possible presence of other low-lying isomers in the photodetachment spectra, as we have already

TABLE I. Total magnetic moments (in units of $\left.\mu_{\mathrm{B}}\right)$ of the $\mathrm{Fe}_{\mathrm{n}}(\mathrm{n}=2-8)$ clusters.

\begin{tabular}{|c|c|c|c|c|c|c|c|c|c|c|}
\hline $\mathrm{n}$ & Reference 3 & Reference 4 & Reference 5 & Reference 6 & Reference 7 & Reference 8 & Reference 34 & Reference 35 & Reference 36 & Present \\
\hline 2 & 6 & 6 & 6 & 6 & 6 & 6 & 6 & 6 & 6 & 6 \\
\hline 3 & 8 & 8 & 8 & 10 & 8 & 10 & 8 & 10 & 10 & 10 \\
\hline 4 & 12 & 12 & 12 & 14 & 12 & 12 & 12 & 14 & 14 & 14 \\
\hline 5 & 16 & 14 & 16 & 16 & 16 & 16 & 14.6 & 15.9 & 16 & 16 \\
\hline 6 & & 20 & 20 & 20 & 20 & 20 & & & 20 & 20 \\
\hline 7 & & 22 & 22 & & 22 & 22 & & & 22 & 22 \\
\hline 8 & & & 24 & & 24 & 24 & & & 24 & 24 \\
\hline
\end{tabular}



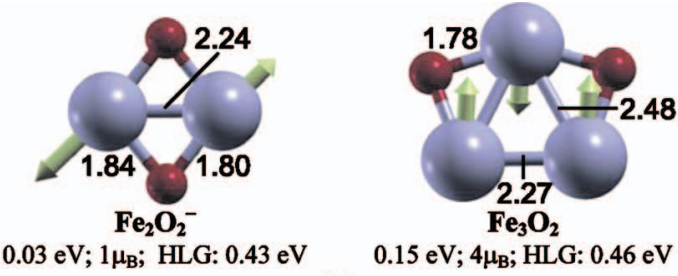

(a)
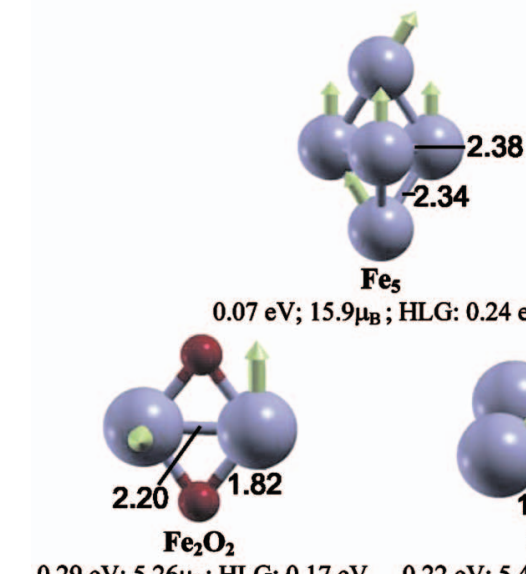

$.9 \mu_{\mathrm{B}} ; \mathrm{HLG}: 0.24 \mathrm{eV}$

$0.29 \mathrm{eV} ; 5.26 \mu_{\mathrm{B}} ; \mathrm{HLG}: 0.17 \mathrm{eV}$
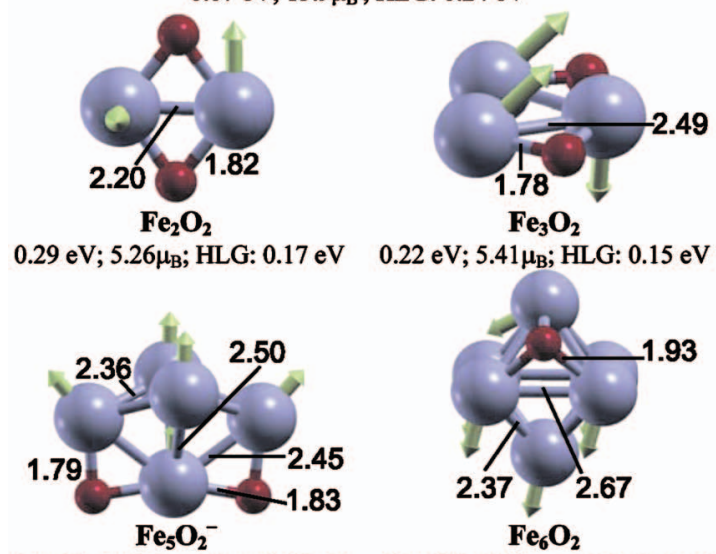

$0.17 \mathrm{eV} ; 14.85 \mu_{\mathrm{B}} ;$ HLG: $0.09 \mathrm{eV}$

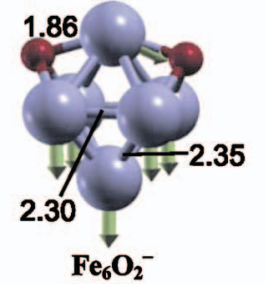

$0.14 \mathrm{eV} ; 17.44 \mu_{\mathrm{B}} ;$ HLG: $0.25 \mathrm{eV}$

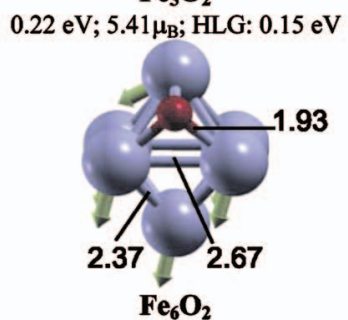

$0.01 \mathrm{eV} ; 19.03 \mu_{\mathrm{B}} ;$ HLG: $0.40 \mathrm{eV}$

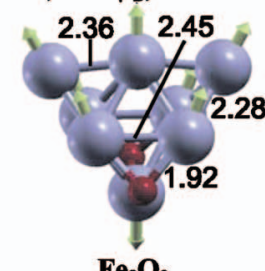

$\mathrm{Fe}_{8} \mathrm{O}_{2}$

$0.29 \mathrm{eV} ; 15.42 \mu_{\mathrm{B}} ; \mathrm{HLG}$ : $0.25 \mathrm{eV}$

(b)

FIG. 3. The total magnetic moment and HLG of the metastable (a) antiferromagnetic and (b) noncollinear magnetic clusters. The blue (bigger) spheres are the iron atoms while the red (smaller) spheres represent oxygen atoms. The arrows indicate the direction of the local spin moments. discussed in Sec. II. Also, it is interesting to note that calculated AEA using the ferromagnetic ground state of $\mathrm{Fe}_{5}(1.90$ $\mathrm{eV})$ is closer to the corresponding experimental value $(1.84 \pm 0.06 \mathrm{eV})$ compared to the value obtained by using its noncollinear analog $(1.96 \mathrm{eV})$.

\section{B. $\mathrm{Fe}_{\mathrm{n}} \mathrm{O}_{2}$ and $\mathrm{Fe}_{\mathrm{n}} \mathrm{O}_{2}^{-}(\mathrm{n}=2-8)$}

The ground state structures of oxides of the neutral and anionic iron clusters for cluster size, $n=2-8$, with their respective total magnetic moments and HLG are presented in Fig. 1. Both the neutral and anionic oxides for $n=2$ possess a $D_{2 h}$ symmetry with a small expansion in the bond lengths (Fe-Fe: $0.01 \AA$ and $\mathrm{Fe}-\mathrm{O}: 0.02 \AA$ ) for $\mathrm{Fe}_{2} \mathrm{O}_{2}^{-}$. The $\mathrm{O}_{2}$ molecule is broken into atoms and associated with the $\mathrm{Fe}_{2}$ and $\mathrm{Fe}_{2}{ }^{-}$dimers. Although the neutral $\mathrm{Fe}_{2} \mathrm{O}_{2}$ is found to be antiferromagnetic, its anionic cluster provides a noncollinear ground state with a total magnetic moment of $2.84 \mu_{\mathrm{B}}$. The corresponding noncollinear angle between the spin directions is $135^{\circ}$. The modulus of the local magnetic moment on each iron atoms in the $\mathrm{Fe}_{2} \mathrm{O}_{2}{ }^{-}$is found to be $2.96 \mu_{\mathrm{B}}$. The noncollinear ground state for $\mathrm{Fe}_{2} \mathrm{O}_{2}{ }^{-}$is $0.03 \mathrm{eV}$ more stable compared to its antiferromagnetic $\left(1 \mu_{\mathrm{B}}\right)$ analog. It may be noted the total magnetic moment of the $\mathrm{Fe}_{2}\left(6 \mu_{\mathrm{B}}\right)$ and $\mathrm{Fe}_{2}{ }^{-}$ $\left(7 \mu_{\mathrm{B}}\right)$ are reduced in their oxides due to their antiferromagnetic and noncollinear ground states, respectively. As we have seen, $\mathrm{Fe}_{2}$ and $\mathrm{Fe}_{2}{ }^{-}$present a ferromagnetic ground state. The antiferromagnetic and noncollinear couplings in $\mathrm{Fe}_{2} \mathrm{O}_{2}$ and $\mathrm{Fe}_{2} \mathrm{O}_{2}{ }^{-}$are induced by the oxygen atoms and can be qualitatively understood by analyzing the charge transfer in these clusters. In the neutral $\mathrm{Fe}_{2} \mathrm{O}_{2}$ almost two electrons are transferred from $\mathrm{Fe}$ to $\mathrm{O}$. We can think of $\mathrm{Fe}_{2}{ }^{2+}$ as being similar to $\mathrm{Cr}_{2}$, and actually the ground state of $\mathrm{Fe}_{2} \mathrm{O}_{2}$ is antiferromagnetic. However, for $\mathrm{Fe}_{2} \mathrm{O}_{2}{ }^{-}$the extra electron goes to the $\mathrm{Fe}$ atoms and there is a competition between ferro- and antiferromagnetic couplings, leading to a noncollinear arrangement.

All the other higher size iron oxides, $\mathrm{Fe}_{\mathrm{n}} \mathrm{O}_{2}$ and $\mathrm{Fe}_{\mathrm{n}} \mathrm{O}_{2}{ }^{-}$ $(n=3-8)$, are found to be ferromagnetic. For $n=3$, the three iron atoms form an isosceles triangle with bond distances as 2.25 and $2.45 \AA$ and 2.18 and $2.41 \AA$ for the neutral and anionic oxides, respectively. The ground state structures of the oxides show that the adsorption of $\mathrm{O}_{2}$ molecules on $\mathrm{Fe}_{3}$

TABLE II. AEA and VDE of $\mathrm{Fe}_{\mathrm{n}}(\mathrm{n}=2-8), \mathrm{Fe}_{2} \mathrm{O}_{2}$, and $\mathrm{Fe}_{3} \mathrm{O}_{2}$ clusters.

\begin{tabular}{|c|c|c|c|c|c|c|c|}
\hline \multirow[b]{2}{*}{ Molecule } & \multirow[b]{2}{*}{ M } & \multicolumn{2}{|c|}{$\begin{array}{l}\text { AEA } \\
(\mathrm{eV})\end{array}$} & \multicolumn{2}{|c|}{$\begin{array}{c}\text { VDE-1 } \\
(\mathrm{eV})\end{array}$} & \multicolumn{2}{|c|}{$\begin{array}{c}\text { VDE-2 } \\
(\mathrm{eV})\end{array}$} \\
\hline & & Expt. $^{a}$ & Theor. & Expt. $^{\mathrm{a}}$ & Theor. & Expt. $^{a}$ & Theor. \\
\hline $\mathrm{Fe}_{2}$ & 7 & $0.902 \pm 0.008$ & 0.97 & 0.90 & 1.01 & 1.44 & 1.38 \\
\hline $\mathrm{Fe}_{3}$ & 11 & $1.43 \pm 0.06$ & 1.51 & 1.55 & 1.68 & 2.06 & 1.71 \\
\hline $\mathrm{Fe}_{4}$ & 15 & $1.78 \pm 0.06$ & 1.79 & 1.83 & 1.90 & 1.98 & 2.10 \\
\hline $\mathrm{Fe}_{5}$ & 17 & $1.84 \pm 0.06$ & 1.90 & 1.90 & 1.91 & 2.03 & 1.93 \\
\hline $\mathrm{Fe}_{6}$ & 21 & $1.58 \pm 0.06$ & 1.62 & 1.72 & 1.74 & 2.07 & 2.12 \\
\hline $\mathrm{Fe}_{7}$ & 23 & $1.50 \pm 0.06$ & 1.60 & 1.67 & 1.73 & 2.31 & 2.14 \\
\hline $\mathrm{Fe}_{8}$ & 25 & $1.76 \pm 0.06$ & 1.50 & 1.77 & 1.75 & 2.07 & 2.12 \\
\hline $\mathrm{Fe}_{2} \mathrm{O}_{2}$ & 1 & 1.40 & 1.41 & 1.40 & 1.43 & 2.36 & 2.41 \\
\hline $\mathrm{Fe}_{3} \mathrm{O}_{2}$ & 13 & 1.81 & 1.79 & 1.82 & 1.86 & 2.50 & 2.48 \\
\hline
\end{tabular}

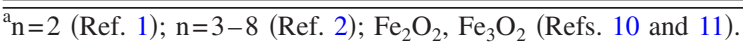


or $\mathrm{Fe}_{3}{ }^{-}$is dissociative. Although the total magnetic moment is enhanced in $\mathrm{Fe}_{3} \mathrm{O}_{2}\left(12 \mu_{\mathrm{B}}\right)$, the moment of $\mathrm{Fe}_{3} \mathrm{O}_{2}{ }^{-}$is reduced for its anionic analog. Both $\mathrm{Fe}_{4} \mathrm{O}_{2}$ and $\mathrm{Fe}_{4} \mathrm{O}_{2}{ }^{-}$possess $C_{s}$ symmetry with association of the dissociated $\mathrm{O}$ atoms, one on a plane and the other on an edge of tetrahedral $\mathrm{Fe}_{4}$. For $\mathrm{n}=5$, both dissociated $\mathrm{O}$ atoms are linked up on the edges of $\mathrm{Fe}_{5}$ and $\mathrm{Fe}_{5}{ }^{-}$clusters possessing a $C_{2 v}$ symmetry. The oxidation of next two higher size oxides does not change the original shape of the $\mathrm{Fe}_{\mathrm{n}}$ and $\mathrm{Fe}_{\mathrm{n}}{ }^{-}(\mathrm{n}=6,7)$. The oxidation of $\mathrm{Fe}_{\mathrm{n}}$ and $\mathrm{Fe}_{\mathrm{n}}{ }^{-}$clusters for $\mathrm{n}=4-7$ does not lead to any enhancement of their magnetic moments as they form $\mathrm{Fe}_{\mathrm{n}} \mathrm{O}_{2}$ and $\mathrm{Fe}_{\mathrm{n}} \mathrm{O}_{2}^{-}$. The ground state structures for the neutral and anionic oxides are similar except for the cluster size eight, where the structure is altered. Although addition of an $\mathrm{O}_{2}$ molecule enhances the magnetic moment in $\mathrm{Fe}_{8}{ }^{-}$cluster to form $\mathrm{Fe}_{8} \mathrm{O}_{2}{ }^{-}\left(25 \mu_{\mathrm{B}}\right)$, for the neutral analog it does not. The $\mathrm{Fe}-\mathrm{Fe}$ bond lengths for the complete series of oxide clusters varies between 2.18 and $2.75 \AA$, whereas $\mathrm{Fe}-\mathrm{O}$ distance ranges between 1.75 and $2.04 \AA$. Although HLG is generally higher for the pure anionic iron clusters compared to their neutral analogs, their oxides show lower HLG compared to corresponding neutrals.

The experimental and theoretical AEA and VDE for the $\mathrm{Fe}_{2} \mathrm{O}_{2}$ and $\mathrm{Fe}_{3} \mathrm{O}_{2}$ oxides are presented in Table II. The calculated AEA $(1.41 \mathrm{eV})$ using noncollinear $\mathrm{Fe}_{2} \mathrm{O}_{2}{ }^{-}$provides an excellent agreement with the experimental value $(1.40$ eV). To calculate the VDE for $\mathrm{Fe}_{2} \mathrm{O}_{2}{ }^{-}$, we performed a neutral calculation with noncollinear anionic geometry along with its spin direction to reach self-consistency. It is found that the direction of the spin relaxed to an antiferromagnetic state $\left(\begin{array}{ll}0 & \mu_{\mathrm{B}}\end{array}\right)$ in the single point neutral calculation. For calculation of the other VDE, we have fixed the total magnetic moment as $2 \mu_{\mathrm{B}}$ and did the neutral calculation with $\mathrm{Fe}_{2} \mathrm{O}_{2}{ }^{-}$ geometry. The calculated VDEs $(1.43$ and $2.41 \mathrm{eV})$ for the noncollinear structure are in good match with the experimental VDEs $(1.40$ and $2.36 \mathrm{eV})$. The corresponding antiferromagnetic $\mathrm{Fe}_{2} \mathrm{O}_{2}^{-}$geometry has VDEs of 1.44 and $2.49 \mathrm{eV}$. This result reinforces the need of considering noncollinear magnetic arrangements when they are plausible: The reasonable agreement between VDEs for the collinear antiferromagnetic $\mathrm{Fe}_{2} \mathrm{O}_{2}{ }^{-}$and the experimental results could lead to the wrong conclusion that it is the ground state, when the noncollinear one is lower in energy and presents a slightly better agreement with the photoelectron experiments.

In the structural optimization process, we have found several antiferromagnetic structures within the relative energy range of $0.03-1.35 \mathrm{eV}$ and few noncollinear metastable structures within $0.3 \mathrm{eV}^{42}$ Figure 3 presents two antiferromagnetic, viz., $\mathrm{Fe}_{2} \mathrm{O}_{2}^{-}(0.03 \mathrm{eV})$ and $\mathrm{Fe}_{3} \mathrm{O}_{2}(0.15 \mathrm{eV})$ and six noncollinear metastable iron oxides close to their ferromagnetic ground state in energy. We have found noncollinear neutral oxides, viz., $\mathrm{Fe}_{2} \mathrm{O}_{2}(0.29 \mathrm{eV}), \mathrm{Fe}_{3} \mathrm{O}_{2}(0.22 \mathrm{eV})$, $\mathrm{Fe}_{6} \mathrm{O}_{2}(0.01 \mathrm{eV})$, and $\mathrm{Fe}_{8} \mathrm{O}_{2}(0.29 \mathrm{eV})$, as well two anionic oxides, viz., $\mathrm{Fe}_{5} \mathrm{O}_{2}{ }^{-}(0.17 \mathrm{eV})$ and $\mathrm{Fe}_{6} \mathrm{O}_{2}{ }^{-}(0.14 \mathrm{eV})$. It may be noted that the presence of such a number of noncollinear low-lying excited states, which includes an almost degenerate $\mathrm{Fe}_{6} \mathrm{O}_{2}(0.01 \mathrm{eV})$, indicates the involvement of noncollinearity in the $\mathrm{O}_{2}$ adsorption process on the iron cluster surface.

\section{CONCLUSIONS}

The structural, electronic, and magnetic properties of $\mathrm{Fe}_{\mathrm{n}}$ and $\mathrm{Fe}_{\mathrm{n}}^{-}$clusters and their oxides, $\mathrm{Fe}_{\mathrm{n}} \mathrm{O}_{2}$ and $\mathrm{Fe}_{\mathrm{n}} \mathrm{O}_{2}^{-}$, with $\mathrm{n}=2-8$, have been studied within a gradient corrected density functional framework, including a systematic study of possible noncollinear alignments of the spin moments. For the pure $\mathrm{Fe}_{\mathrm{n}}$ clusters, we have seen that the addition of an electron neither changes the predicted ground state structures nor the ferromagnetic coupling. The magnetic moments increase by $1 \mu_{\mathrm{B}}$ for the smaller sizes $(\mathrm{n}=2-5)$, while they decrease $1 \mu_{\mathrm{B}}$ for the rest. For the oxidized clusters we have shown that the two oxygen atoms are completely dissociated on the Fe cluster surface. Oxygen induces a competition between ferromagnetic, noncollinear, and antiferromagnetic couplings, which makes the ground state of $\mathrm{Fe}_{2} \mathrm{O}_{2}$ to be antiferromagnetically coupled, and its anion to present a noncollinear configuration. We would like to add that while our studies predict collinear ground states for most clusters, we do find noncollinear states energetically close to the ground states in most cases. It should be possible to access these states at high temperatures or as the clusters are deposited on surfaces. We hope that the present work would encourage such experiments.

\section{ACKNOWLEDGMENTS}

The authors gratefully acknowledge support from ERC, Inc. through Award No. RS080281.

${ }^{1}$ D. G. Leopold and W. C. Lineberger, J. Chem. Phys. 85, 51 (1986).

${ }^{2}$ L. S. Wang, X. Li, and H. F. Zhang, Chem. Phys. 262, 53 (2000).

${ }^{3}$ M. Castro and D. R. Salahub, Phys. Rev. B 49, 11842 (1994).

${ }^{4}$ P. Ballone and R. O. Jones, Chem. Phys. Lett. 233, 632 (1995).

${ }^{5}$ O. Diéguez, M. M. G. Alemany, and C. Rey, Phys. Rev. B 63, 205407 (2001).

${ }^{6}$ G. L. Gutsev and C. W. Bauschlicher, Jr., J. Phys. Chem. A 107, 7013 (2003).

${ }^{7}$ C. Köhler, G. Seifert, and T. Frauenheim, Chem. Phys. 309, 23 (2005).

${ }^{8}$ S. Yu, S. Chen, W. Zhang, L. Yu, and Y. Yin, Chem. Phys. Lett. 446, 217 (2007).

${ }^{9}$ G. L. Gutsev, S. N. Khanna, and P. Jena, Phys. Rev. B 62, 1604 (2000).

${ }^{10}$ L. S. Wang, H. Wu, and S. R. Desai, Phys. Rev. Lett. 76, 4853 (1996).

${ }^{11}$ H. Wu, S. R. Desai, and L. S. Wang, J. Am. Chem. Soc. 118, 5296 (1996).

${ }^{12}$ J. Fan and L. S. Wang, J. Chem. Phys. 102, 8714 (1995).

${ }^{13}$ N. M. Reilly, J. U. Reveles, G. E. Johnson, S. N. Khanna, and A. W. Castleman, J. Phys. Chem. A 111, 4158 (2007).

${ }^{14}$ N. M. Reilly, J. U. Reveles, G. E. Johnson, J. M. del Campo, S. N. Khanna, A. M. Köster, and A. W. Castleman, Jr., J. Phys. Chem. C 111, 19086 (2007).

${ }^{15}$ H. Shiroishi, T. Oda, I. Hamada, and N. Fujima, Mol. Simul. 30, 911 (2004).

${ }^{16}$ H. Shiroishi, T. Oda, I. Hamada, and N. Fujima, Polyhedron 24, 2472 (2005).

${ }^{17}$ N. O. Jones, B. V. Reddy, F. Rasouli, and S. N. Khanna, Phys. Rev. B 72, 165411 (2005).

${ }^{18}$ X.-Q. Li and W.-X. Zhang, Langmuir 22, 4638 (2006).

${ }^{19}$ K.-C. Wu, Y.-L. Tung, Y.-L. Chen, and Y.-W. Chen, Appl. Catal., B 53, 111 (2004).

${ }^{20}$ A. I. Kozlov, A. P. Kozlova, H. Liu, and Y. Iwasawa, Appl. Catal., A 182, 9 (1999)

${ }^{21}$ H.-Y. Lin and Y.-W. Chen, Ind. Eng. Chem. Res. 44, 4569 (2005).

${ }^{22}$ I. M. L. Billas, A. Chatelain, and W. A. De Heer, Science 265, 1682 (1994).

${ }^{23}$ H.-J. Fan, C.-W. Liu, and M.-S. Liao, Chem. Phys. Lett. 273, 353 (1997).

${ }^{24}$ A. Sebetci, Chem. Phys. 354, 196 (2008).

${ }^{25}$ G. E. Johnson, J. U. Reveles, N. M. Reilly, E. C. Tyo, S. N. Khanna, and 
A. W. Castleman, Jr., J. Phys. Chem. A 112, 11330 (2008).

${ }^{26}$ F. Liu, F.-X. Li, and P. B. Armentrouta, J. Chem. Phys. 123, 064304 (2005).

${ }^{27}$ G. L. Arvizu and P. Calaminici, J. Chem. Phys. 126, 194102 (2007).

${ }^{28}$ M. Ichihashi, T. Hanmura, R. T. Yadav, and T. Kondow, J. Phys. Chem. A 104, 11885 (2000).

${ }^{29}$ J. M. D. Coey, Can. J. Phys. 65, 1210 (1987).

${ }^{30}$ F. Keffer, in Encyclopedia of Physics, edited by H. P. J. Wijn (Springer, Berlin, 1966), Vol. 18, p. 2.

${ }^{31}$ L. M. Sandratskii and P. G. Guletskii, J. Phys F: Met. Phys. 16, L43 (1986).

${ }^{32}$ J. Kübler, K. H. Höck, and J. Sticht, J. Appl. Phys. 63, 3482 (1988).

${ }^{33}$ H. C. Herper, E. Hoffmann, and P. Entel, Phys. Rev. B 60, 3839 (1999).

${ }^{34}$ T. Oda, A. Pasquarello, and R. Car, Phys. Rev. Lett. 80, 3622 (1998).

${ }^{35}$ D. Hobbs, G. Kresse, and J. Hafner, Phys. Rev. B 62, 11556 (2000).
${ }^{36}$ G. Rollmann, P. Entel, and S. Sahoo, Comput. Mater. Sci. 35, 275 (2006).

${ }^{37}$ P. Hohenberg and W. Kohn, Phys. Rev. B 136, B864 (1964).

${ }^{38}$ W. Kohn and L. J. Sham, Phys. Rev. A 140, A1133 (1965).

${ }^{39}$ J. P. Perdew, K. Burke, and M. Ernzerhof, Phys. Rev. Lett. 77, 3865 (1996).

${ }^{40}$ G. Kresse and J. Hafner, J. Phys.: Condens. Matter 6, 8245 (1994).

${ }^{41}$ G. Kresse and J. Furthmuller, Phys. Rev. B 54, 11169 (1996).

${ }^{42}$ See supplementary material at http://dx.doi.org/10.1063/1.3425879 for the various initial and final optimized structures of $\mathrm{Fe}_{\mathrm{n}}, \mathrm{Fe}_{\mathrm{n}}^{-}, \mathrm{Fe}_{\mathrm{n}} \mathrm{O}_{2}$, and $\mathrm{Fe}_{\mathrm{n}} \mathrm{O}_{2}^{-}(\mathrm{n}=2-8)$ clusters.

${ }^{43}$ M. Moskovits, D. P. DiLella, and W. Limm, J. Chem. Phys. 80, 626 (1984).

${ }^{44}$ J. P. Perdew and Y. Wang, Phys. Rev. B 45, 13244 (1992). 